\title{
An Analysis of the Use of Complementary and Alternative Therapies in Patients with Breast Cancer
}

\author{
M. Oktay Tarhan ${ }^{\mathrm{a}} \quad$ Ugur Muslu $^{\mathrm{b}} \quad$ Isil Somali $^{\mathrm{a}}$ Cigdem Erten $^{\mathrm{a}} \quad$ Ahmet Alacacioglu $^{\mathrm{a}}$ \\ Sengul Varol ${ }^{\mathrm{a}}$ S. Leyla Aslan ${ }^{\mathrm{b}}$ \\ ${ }^{a}$ Clinic of Medical Oncology, \\ b 3 rd Clinic of Internal Medicine, Izmir Ataturk Training and Research Hospital, Izmir, Turkey
}

\section{Key Words}

Breast cancer - Complementary and alternative therapy . Quality of life

\section{Summary}

Background: The aim of the present study was to investigate the use of complementary and alternative medicine (CAM) and the factors that influence their use in patients with breast cancer. Patients and Methods: This descriptive and cross-sectional study was carried out with 135 breast cancer patients on chemotherapy. Results: $30.4 \%$ of patients admitted using one or more CAM methods. The most common method was herbal therapy (97.6\%). There were statistically significant differences among CAM users and non-users in terms of time elapsed since initial diagnosis, current stage of the disease, and current type of therapy. As the time since the initial diagnosis increased, so did the percentage of CAM users. Those patients with advanced stage cancer or relapsed disease who were receiving palliative therapy used CAM methods more than those receiving adjuvant therapy. As far as quality of life was concerned, symptoms such as nausea and vomiting, dyspnea, and diarrhea were more common among CAM users. Conclusion: It is important and necessary that health professionals working in oncology clinics are made aware of the common use of CAM methods so that they can provide the necessary communication between patients and other health professionals on these treatment modalities.

\section{Schlüsselwörter}

Brustkrebs · Komplementäre und alternative Therapie . Lebensqualität

\section{Zusammenfassung}

Hintergrund: Ziel dieser Studie war es, die Anwendung komplementär- und alternativmedizinischer (CAM) Methoden sowie Faktoren, die deren Einsatz bei Brustkrebspatienten beeinflussen, zu untersuchen. Patienten und Methoden: Die vorliegende beschreibende Querschnittsstudie wurde mit 135 chemotherapeutisch behandelten Brustkrebspatientinnen durchgeführt. Ergebnisse: $30.4 \%$ der Patientinnen gaben an, eine oder mehrere CAM-Methoden anzuwenden. Am häufigsten wurden kräutermedizinische Methoden eingesetzt (97.6\%). Zwischen Benutzern und Nicht-Benutzern von CAM betanden statistisch signifikante Unterschiede bezüglich der Zeit seit Erstdiagnose, dem aktuellen Krankheitsstadium und der derzeitig angewendeten Therapieform. Mit wachsender Zeitspanne seit Erstdiagnose nahm auch der Anteil an CAM-Benutzern zu. Palliativ behandelte Patientinnen im fortgeschrittenen oder rezidivierten Stadium wendeten CAM häufiger an als adjuvant behandelte Patientinnen. In Bezug auf die Lebensqualität waren Symptome wie Übelkeit und Erbrechen, Dyspnoe und Durchfall unter CAM-Benutzern weiter verbreitet. Schlussfolgerung: Es ist wichtig und notwendig, dass sich in der Onkologie tätige Mediziner der Existenz von CAM-Methoden bewusst werden, so dass sie die nötige Kommunikation zwischen Patienten und Angehörigen anderer Gesundheitsberufe hinsichtlich dieser Behandlungsmodalitäten bereitstellen können.

\section{KARGER}

Fax +497614520714

Information@Karger.de

www.karger.com (c) 2009 S. Karger GmbH, Freiburg

www.karger.com/brc
Oktay Tarhan, MD

Ataturk Training and Research Hospital

Medical Oncology, Izmir, Turkey

Tel. +90 2322444444

dralaca2000@yahoo.com 


\section{Introduction}

Rapid developments in the diagnosis and treatment of diseases brought forth an increase in the use of complementary and alternative medicine (CAM) practices. Increments in hard to treat, chronic, aggressive, and malign diseases, the high cost of new technologies, the difficulties the patients face to obtain medical facilities, the physicians' inability to focus sufficiently on each patient's demands - all suspects against the efficiency and adverse effects of current therapeutic approaches - in parallel to an increase in life expectancy have increased the popularity of CAM practices among consumers [1].

CAM, as defined by The National Center for Complementary and Alternative Medicine (NCCAM) in the USA, is a group of diverse medical and health care systems, practices, and products that are not presently considered to be part of conventional Western medicine. NCCAM classifies CAM therapies into 5 categories: alternative medical systems, mindbody interventions, biologically based therapies, manipulative and body-based methods, and energy therapies [2]. The results of a systematic review have shown that the prevalence of use of CAM ranges from 9 to $65 \%$ and it continues to rise [3].

Surveys undertaken in Turkey demonstrate a prevalence of $36-70 \%$ for CAM practices, with herbal therapies being the most commonly used type of these practices [4-11]. The Aegean region of Turkey has a distinct floral characteristic, and data on the use of CAM practices are fairly limited. Survey results have shown that the use of CAM practices are more popular among women. Breast cancer is predominantly (99\%) seen in female patients, and data on the use of CAM methods in breast cancer patients are also limited. Some of the studies undertaken to determine the use of these practices have revealed that the patient's age, educational level, marital status, income level, and the availability of health insurance are among the main sociodemographic factors that affect the use of CAM practices [12-14]. On the other hand, clinical features of the disease such as receiving chemotherapy or radiotherapy, recurrence, or metastasis of the tumor also affect the use of CAM practices [15].

A diagnosis of cancer and the side effects of cancer therapy affect the quality of life in these patients. Studies have shown that the use of CAM practices is more common among patients with low quality of life scores [16], although some controversial reports have also been published [17]. In the present study we aimed to investigate the frequency of the use of CAM therapies and the factors that influence their use, including sociodemographic factors, clinical features of the disease, and quality of life, in patients with breast cancer.

\section{Patients and Methods}

The present study is a descriptive and cross-sectional investigation undertaken to assess the use of CAM therapies and the factors that influence their use in patients with breast cancer. The sampling procedure used was nonprobability sampling. A total of 135 breast cancer patients who were receiving chemotherapy at the Medical Oncology Outpatient Clinic of the zmir Atatürk Training and Research Hospital between April and June 2008 were included in the study. Exclusion criteria were: having problems with communication, no desire to take part in the study, being in the terminal stage of the disease, or having any health problem requiring urgent care. Before the initiation of the study, its protocol was approved by the hospital ethics committee, and informed consent of the patients was obtained. For ethical reasons, the names of the patients enrolled in the study remain undisclosed. The aim of the study was explained to each patient, and patients over 18 years of age and volunteering to take part in the study were enrolled after written consent was obtained. Before starting the study, the consent of the EORTC QLQ-C30 Quality of Life Group was also obtained. The 'Sociodemographic Characteristics Questionnaire' and the 'Complementary and Alternative Therapy Use Assessment Form' were used to collect the patient data. Additionally, a quality of life-assessing questionnaire (EORTC QOL-C30) was answered.

\section{Sociodemographic Characteristics Questionnaire}

This form was developed by the researcher in order to collect data on the sociodemographic features of the patients enrolled in the study, including age, marital status, educational status, profession, social assurance, economical status, and location of longest residence. Information regarding the patients' disease or clinical features such as time of diagnosis, disease stage at time of diagnosis, present stage of the disease, and type of treatment was collected by review of the patients' medical records.

Complementary and Alternative Therapy Use Assessment Form Information regarding the patients' therapy type, reasons of use, time of therapy commencement, sources of information on CAM therapy, awareness of physicians about the patients' use of CAM methods, whether the patients requested information from health professionals on CAM methods, the success of the CAM method used, the frequency of CAM use, and therapy-related adverse effects was collected through the use of the Complementary and Alternative Therapy Use Assessment Form.

\section{Quality of Life Assessment Questionnaire (EORTC QLQ-C30)}

The questionnaire was prepared by Aaronson and coworkers and consists of 30 items and 2 modules, including the functional status and symptoms scale. The functional status module consists of 6 different submodules, including physical (questions 1-5), role (questions 6 and 7), cognitive (questions 20 and 25), emotional (questions 21-24), social (questions 26 and 27), and global quality of life (questions 29 and 30) submodules. The symptoms scale includes symptoms such as fatigue (questions 10, 12, and 18), nausea and vomiting (questions 14 and 15), pain (questions 9 and 19), dyspnea (question 8), sleeping disorder (question 11), loss of appetite (question 13), constipation (question 16), diarrhea (question 17), and economic impact or financial difficulties (question 28). Higher scores obtained from the scale indicate a high functional state and a high degree of severity of symptoms. This scale was adapted to the Turkish language by Guzelant and coworkers, and its validity and safety for the Turkish population in patients with lung cancer has been demonstrated. The Cronbach alpha coefficient of the scale was set as $\geq 0.70$ [18]. The evaluation process of the scale was performed according to the instructions in the EORTC QLQ-C30 Scoring Manual.

\section{Collection of Data}

The questionnaires were filled in by the researcher during a face to face interview with each patient. Before starting to fill in the questionnaires, the researcher gave the patients some information on CAM in order to help them understand the procedure.

\section{Data Analysis}

Number and percentage distributions were used in the analysis of all data. The association between the use of complementary and alternative 
Table 1. Sociodemographic features of the patients

\begin{tabular}{lc}
\hline Sociodemographic features & Patients, $\mathrm{n}(\%)$ \\
\hline Age group, years & $29(21.5)$ \\
$30-39$ & $46(21.5)$ \\
$40-49$ & $60(44.4)$ \\
$\geq 50$ & \\
Marital status & $108(80.0)$ \\
$\quad$ Married & $27(20.0)$ \\
Single & \\
Education status & $33(24.5)$ \\
Illiterate & $79(58.5)$ \\
Primary school & $23(17.0)$ \\
High school & \\
Occupation & $114(84.4)$ \\
$\quad$ Housewife & $21(15.6)$ \\
Employed & \\
Monthly income & $90(66.7)$ \\
Less than monthly expenditure & $45(33.3)$ \\
Equal to monthly expenditure & \\
Location of longest residence & $40(29.6)$ \\
Village & $49(36.3)$ \\
Small town & $46(34.1)$ \\
City &
\end{tabular}

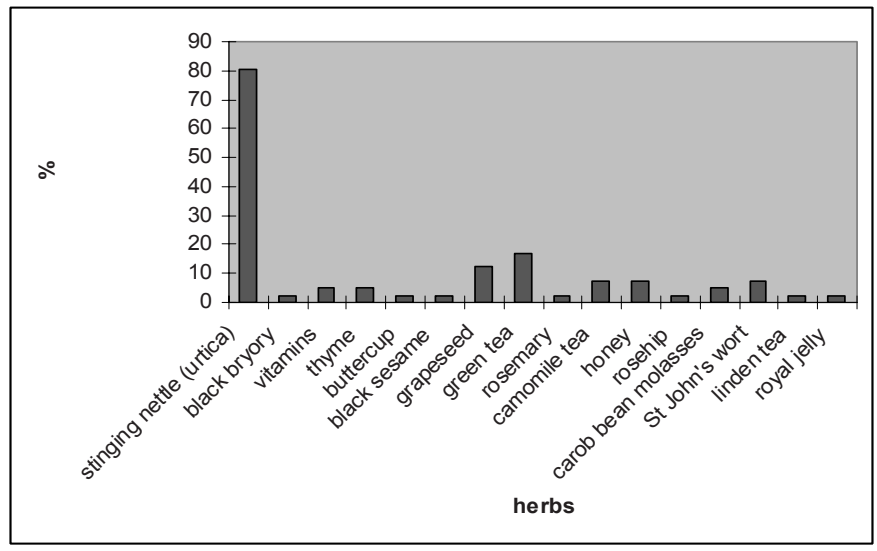

Fig. 1. Distribution of herbal therapies used among the patients (more than one herbal remedy was reported).

therapy in patients with breast cancer and sociodemographic and clinical features of each patient was assessed by $\chi^{2}$ analysis. The difference in quality of life levels between users and non-users of CAM methods was investigated using the student's t test.

\section{Results}

The sociodemographic features of the 135 patients participating in the study are summarized in table 1 and the clinical features in table 2. Among the participants, 41 (30.4\%) used one or more CAM methods. Among these patients,
Table 2. Clinical features of the patients

\begin{tabular}{lc}
\hline Clinical features & Patients, $\mathrm{n}(\%)$ \\
\hline Time since diagnosis, months & $69(51.1)$ \\
$0-6$ & $18(13.3)$ \\
$6-12$ & $48(35.6)$ \\
13 and over & \\
Age at time of diagnosis & $21(15.6)$ \\
$30-39$ & $106(78.5)$ \\
$40-49$ & $8(5.9)$ \\
$\geq 50$ & \\
Current stage of disease & $20(14.8)$ \\
Local & $84(62.2)$ \\
Locally advanced & $31(23.0)$ \\
Advanced & \\
Diseases status & $110(81.5)$ \\
Primary & $25(18.5)$ \\
Relapse & \\
Type of current therapy & $58(43.0)$ \\
Palliative & $77(57.0)$ \\
Adjuvant & \\
\hline
\end{tabular}

$40(97.6 \%)$ used herbal remedies and 1 patient confirmed that she used mind-body interventions. As seen in figure 1, the most commonly used herbal therapy was stinging nettle (urtica). Twenty-five (61\%) patients reported that they used CAM methods in order to support the conventional medical therapy prescribed by their physicians, 14 (34\%) patients used these methods because they were affected by their social environments, and $2(5 \%)$ patients used them for comfort and relaxation. The majority $(68.3 \%)$ of the patients started using CAM methods at the time of initial diagnosis while $31.7 \%$ started using these methods when the disease was in the advanced stage. Among these patients, 58.5\% admitted using CAM methods from time to time while $41.5 \%$ used them regularly. The majority $(63.4 \%)$ of the patients admitted that they obtained information on CAM methods from other family members, $17.1 \%$ from friends, $14.6 \%$ from the media, and $4.9 \%$ from health professionals. Most (61\%) patients used CAM methods when they were not on conventional medical therapy, and the remaining $31 \%$ used these methods simultaneously with the conventional medical therapy. In the interviews, the majority $(80.5 \%)$ of the patients reported that CAM methods were beneficial for their health. When they were asked if these methods caused an improvement in their health status, 31.7\% said 'yes', 9.8\% said 'no', and 58.5\% said that they did not know. In total, $73.2 \%$ of the patients thought that their physicians should be aware of their using CAM methods, although only $34.1 \%$ of the patients shared this information with their physicians. Among these patients, 36.6\% reported that they wished to obtain knowledge concerning CAM methods from their physicians while $68.8 \%$ reported that their physicians did not approve of these methods. 
Table 3. Comparison of the patients' status of CAM use grouped according to their sociodemographic features

\begin{tabular}{|c|c|c|c|c|c|}
\hline \multirow[t]{2}{*}{ Sociodemographic features } & \multicolumn{2}{|c|}{$\begin{array}{l}\text { Status of complementary and } \\
\text { alternative therapy use }\end{array}$} & \multirow[t]{2}{*}{ Total, $\mathrm{n}$} & \multirow[t]{2}{*}{$\mathrm{p}$} & \multirow[t]{2}{*}{$\chi^{2}$} \\
\hline & user, n (\%) & non-user, n (\%) & & & \\
\hline Age group, years & & & & $0.059^{\mathrm{a}}$ & 5.657 \\
\hline $30-39$ & $12(41.4)$ & $17(58.6)$ & 29 & & \\
\hline $40-49$ & $17(37.0)$ & $29(63.0)$ & 46 & & \\
\hline$\geq 50$ & $12(20.0)$ & $48(80.0)$ & 60 & & \\
\hline Total & $41(30.4)$ & $94(69.6)$ & 135 & & \\
\hline Marital status & & & & $0.574^{\mathrm{a}}$ & 0.315 \\
\hline Married & $34(31.5)$ & $74(68.5)$ & 108 & & \\
\hline Single & $7(25.9)$ & $20(74.1)$ & 27 & & \\
\hline Total & $41(30.4)$ & 94 (69.6) & 135 & & \\
\hline Education status & & & & $0.873^{\mathrm{a}}$ & 0.271 \\
\hline Illiterate & $10(30.3)$ & $23(69.7)$ & 33 & & \\
\hline Primary school & $23(29.1)$ & $56(70.9)$ & 79 & & \\
\hline High school & $8(34.8)$ & $15(65.2)$ & 23 & & \\
\hline Total & $41(30.4)$ & $94(69.6)$ & 135 & & \\
\hline Employment status & & & & $0.845^{\mathrm{a}}$ & 0.038 \\
\hline Housewife & $35(30.7)$ & 79 (69.3) & 114 & & \\
\hline Employed & $6(28.6)$ & $15(71.4)$ & 21 & & \\
\hline Total & $41(30.4)$ & $94(69.6)$ & 135 & & \\
\hline Level of income & & & & $0.791^{\mathrm{a}}$ & 0.070 \\
\hline Less than monthly expenditure & $28(31.1)$ & $62(68.9)$ & 90 & & \\
\hline Equal to monthly expenditure & $13(28.9)$ & $32(71.1)$ & 45 & & \\
\hline Total & $41(30.4)$ & 94 (69.6) & 135 & & \\
\hline Location of longest residence & & & & $0.688^{\mathrm{a}}$ & 0.747 \\
\hline Village & $14(35.0)$ & $26(65.0)$ & 40 & & \\
\hline Small town & $13(26.5)$ & $36(73.5)$ & 49 & & \\
\hline City & $14(30.4)$ & $32(69.6)$ & 46 & & \\
\hline Total & $41(30.4)$ & $94(69.6)$ & 135 & & \\
\hline
\end{tabular}

There was no statistically significant difference between the patients' sociodemographic characteristics and CAM use status ( $p>0.05$ ) (table 3 ). But when CAM use was assessed based on the disease characteristics, time from initial diagnosis, current stage and status of the disease, and current therapy method, there were statistically significant differences between CAM users and non-users $(\mathrm{p}<0.05)$. As the time from initial diagnosis increased, so did the percentage of patients using CAM. Namely, the percentage of CAM use was higher among patients with advanced disease, relapsed disease, and in patients on palliative therapy, compared to those receiving adjuvant therapy (41.4 vs. $22.1 \%$ ) (table 4 ).

The patients' use of CAM methods based on quality of life submodules is shown in table 5. No statistically significant difference was observed between Global Health and Functional Area submodules between users and non-users of CAM methods ( $p>$ $0.05)$. When the symptom submodules' score averages of users and non-users were compared, nausea and vomiting, dyspnea, and diarrhea were more prominent among CAM users $(\mathrm{p}<$ 0.05 ). There was no statistically significant difference between users and non-users when other symptoms were assessed.

\section{Discussion}

The usage rate and types of CAM vary between patients with breast cancer. In our study, the usage rate was $30.4 \%$, with $97.6 \%$ of the patients using herbal therapies. A study conducted in Japan demonstrated a prevalence of CAM use of $32 \%$ among cancer patients [19]. Another study conducted with women with breast cancer revealed a prevalence of CAM use of $36 \%$ [12]. A study performed in Europe and comprising 282 women with breast cancer showed a $44.7 \%$ usage rate of CAM, with $46.4 \%$ of these patients using herbal therapies [20]. On the other hand, the prevalence of CAM use in Australia was reported to be $14.5 \%$ among women with different types of cancer, and $11.5 \%$ among women with breast cancer [21]. In China, the usage rate of CAM in patients with breast cancer was as high as $98 \%$, with traditional Chinese medicine, dietary supplements, physical exercise, and involvement in self-help groups being among the most popular methods [15]. By contrast, in Iran, prayer and spiritual healing were the most commonly used CAM methods, with a prevalence of $32 \%$ among women with breast cancer [22]. The results 
Table 4. Comparison of the patients' status of CAM use grouped according to their clinical features

\begin{tabular}{|c|c|c|c|c|c|}
\hline \multirow[t]{2}{*}{ Clinical features } & \multicolumn{2}{|c|}{$\begin{array}{l}\text { Status of complementary and } \\
\text { alternative therapy use }\end{array}$} & \multirow[t]{2}{*}{ Total, $\mathrm{n}$} & \multirow[t]{2}{*}{$\mathrm{p}$} & \multirow[t]{2}{*}{$\chi^{2}$} \\
\hline & user, n (\%) & non-user, n (\%) & & & \\
\hline Time since diagnosis, months & & & & $0.033^{\mathrm{a}}$ & 6.830 \\
\hline $0-6$ & $14(20.3)$ & $55(79.7)$ & 69 & & \\
\hline $6-12$ & $7(38.9)$ & $11(61.1)$ & 18 & & \\
\hline 13 and over & 20 (41.7) & $28(58.3)$ & 48 & & \\
\hline Total & $41(30.4)$ & $94(69.6)$ & 135 & & \\
\hline Current stage of the disease & & & & $0.011^{\mathrm{a}}$ & 9.003 \\
\hline Local & $6(30.0)$ & $14(70.0)$ & 20 & & \\
\hline Locally advanced & $19(22.6)$ & $65(77.4)$ & 84 & & \\
\hline Advanced & $16(51.6)$ & $15(48.6)$ & 31 & & \\
\hline Total & $41(30.4)$ & $94(69.6)$ & 135 & & \\
\hline Comorbidities & & & & $0.261^{\mathrm{b}}$ & 1.261 \\
\hline Present & $8(22.9)$ & $27(77.1)$ & 35 & & \\
\hline Absent & $33(33.0)$ & $67(67.0)$ & 100 & & \\
\hline Total & $41(30.4)$ & $94(69.6)$ & 135 & & \\
\hline Disease status & & & & $0.034^{\mathrm{a}}$ & 4.509 \\
\hline Primary & $29(26.4)$ & $81(73.6)$ & 110 & & \\
\hline Relapsed & $12(48.0)$ & $13(52.0)$ & 25 & & \\
\hline Total & $41(30.4)$ & $94(69.6)$ & 135 & & \\
\hline Current therapy & & & & $0.016^{\mathrm{a}}$ & 5.828 \\
\hline Palliative & $24(41.4)$ & 34 (58.6) & 58 & & \\
\hline Adjuvant & $17(22.1)$ & $60(77.9)$ & 77 & & \\
\hline Total & $41(30.4)$ & 94 (69.6) & 135 & & \\
\hline
\end{tabular}

Table 5. Comparison of the patients' status of CAM use grouped according to quality of life subdimensions

\begin{tabular}{|c|c|c|c|c|}
\hline \multirow{2}{*}{$\begin{array}{l}\text { Subdimensions of quality } \\
\text { of life }\end{array}$} & \multicolumn{2}{|l|}{ Status of CAM use } & \multirow[t]{2}{*}{$\mathrm{t}$} & \multirow[t]{2}{*}{$\mathrm{p}$} \\
\hline & $\begin{array}{l}\text { user } \\
(\mathrm{n}=41), X \pm S D\end{array}$ & $\begin{array}{l}\text { non-user } \\
(\mathrm{n}=94), \mathrm{X} \pm \mathrm{SD}\end{array}$ & & \\
\hline Global Health & $64.43 \pm 20.75$ & $67.55 \pm 17.21$ & -0.909 & $0.365^{\mathrm{a}}$ \\
\hline \multicolumn{5}{|l|}{ Function scales } \\
\hline Physical function & $72.68 \pm 21.01$ & $77.51 \pm 15.42$ & -1.493 & $0.138^{\mathrm{a}}$ \\
\hline Role function & $75.60 \pm 20.44$ & $78.36 \pm 19.98$ & -0.733 & $0.465^{\mathrm{a}}$ \\
\hline Emotional function & $72.15 \pm 20.29$ & $75.79 \pm 19.78$ & -0.976 & $0.331^{\mathrm{a}}$ \\
\hline Cognitive function & $85.36 \pm 14.04$ & $88.65 \pm 16.61$ & -1.105 & $0.271^{\mathrm{a}}$ \\
\hline Social function & $69.10 \pm 24.59$ & $76.41 \pm 19.61$ & -1.840 & $0.068^{\mathrm{a}}$ \\
\hline \multicolumn{5}{|l|}{ Symptom scales } \\
\hline Fatigue & $17.61 \pm 15.70$ & $13.94 \pm 15.27$ & 1.272 & $0.206^{\mathrm{a}}$ \\
\hline Nausea and vomiting & $30.08 \pm 38.76$ & $18.79 \pm 20.33$ & 2.215 & $0.028^{\mathrm{b}}$ \\
\hline Pain & $26.25 \pm 27.70$ & $23.04 \pm 21.04$ & 0.730 & $0.466^{\mathrm{a}}$ \\
\hline Dyspnea & $23.57 \pm 13.87$ & $6.38 \pm 16.41$ & 2.820 & $0.006^{\mathrm{b}}$ \\
\hline Sleeping disorder & $29.26 \pm 23.79$ & $28.72 \pm 23.74$ & 0.123 & $0.903^{\mathrm{a}}$ \\
\hline Loss of appetite & $17.88 \pm 21.21$ & $18.08 \pm 25.24$ & 0.044 & $0.965^{\mathrm{a}}$ \\
\hline Constipation & $26.82 \pm 29.07$ & $19.85 \pm 25.54$ & 1.397 & $0.165^{\mathrm{a}}$ \\
\hline Diarrhea & $15.44 \pm 21.2$ & $5.31 \pm 14.08$ & 3.260 & $0.001^{\mathrm{b}}$ \\
\hline Economic difficulties & $36.58 \pm 33.99$ & $28.72 \pm 27.04$ & 1.433 & $0.154^{\mathrm{a}}$ \\
\hline $\begin{array}{l}\mathrm{SD}=\text { Standard deviation. } \\
{ }^{\mathrm{a}} \mathrm{p}>0.05 \\
{ }^{\mathrm{b}} \mathrm{p}<0.05\end{array}$ & & & & \\
\hline
\end{tabular}


of several studies demonstrate that the most popular CAM methods among women with breast cancer are relaxation, massage, high-dose vitamins, and herbal therapies [16, 17]. Recently published systematic reviews investigated antioxidants and other micronutrients in complementary medicine [23], the effect of isoflavones on breast cancer risk [24], and various forms of complementary therapies [25]. In Turkey, the usage rate of CAM is reported to vary between 36 and $70 \%$ among cancer patients, with herbal therapies being the most frequently used method [4-11, 26].

The results of our study suggest that the easy availability, the low costs, the belief that since they are natural remedies they must be harmless, and the presence of herbal remedies in our traditional medical practices and cultural life are some of the reasons for the common use of herbal therapies in Turkey. In the present study, $80.5 \%$ of the patients stated that they used stinging nettle (urtica) which is the most popular herb used for the treatment of cancer $[9,11]$. Most of the patients enrolled in our study started using CAM methods as an adjunct or support to their current therapies, and because other family members recommended it. Another Turkish study revealed that family members and the close social environment were the important factors that affected the patients' decision to initiate CAM methods [26]. Similarly, the study by Molassiotis et al. [20] revealed that $64.2 \%$ of women with breast cancer obtained information on CAM methods from their friends, $30.4 \%$ from the media, and $24.4 \%$ from other family members. In the study by Nagel et al. [12], $60 \%$ of the breast cancer patients reported to have been informed by their doctors on issues regarding CAM, $34 \%$ by the media, $17 \%$ by their friends, and $10 \%$ by other persons [12].

In our study, although most of the patients admitted that CAM methods were beneficial, $58.5 \%$ of them were not fully aware if the use of these methods had caused an improvement in their health status. This may be because our patients perceived these therapies as a part of their daily lives (as food supplements). In the European study [20] to examine the association between anxiety, depression, and quality of life and CAM use among breast cancer patients, $6.5 \%$ reported no beneficial effect for cancer, but the majority reported to be emotionally strengthened and able to cope better with cancer. In the Chinese study [15], most of the patients reported that they benefited from CAM techniques.

Among our patients, $73.2 \%$ felt that their physicians should know they are using CAM methods, but only $34.1 \%$ informed their physicians on their using CAM. Patients usually do not inform their physicians about the CAM methods they are using [27]. The reasons behind this fact may be that either health professionals do not take into account CAM methods during the evaluation of the patients or the patients may feel shy to admit to their use of CAM methods. In this context, the majority of our patients stated that their physicians did not approve of their use of these therapy methods. The insufficiency of clinical studies that firmly establish the benefits of these therapies and the possibility of interactions between these methods and conventional medical therapies may be some of the reasons why physicians do not approve the use of CAM methods in patients with breast cancer.

Although we did not observe a statistically significant difference between the patients' sociodemographic characteristics and CAM use status in our study, the usage rate was lower in patients over 50 years of age and in single patients, while usage was more prevalent in patients living in villages. Studies from Turkey demonstrate that the use of CAM is more prominent among cancer patients with lower levels of education and among female cancer patients [8,11]. Studies from various countries have shown that CAM use is more common among young patients [12-14, 16], patients with high levels of education [12-14], high income levels [15], and in married patients [15]. The reason of higher use of CAM in patients living in villages may be the easier and cheaper availability of herbal products in the villages. The use of CAM methods is more common among younger patients, which may reflect the desire of these patients to find new remedies.

We observed that CAM use increased with the time passed since the initial diagnosis of the disease. Studies conducted with cancer patients from the Eastern Anatolia region revealed a prevalence of $17.8 \%$ before diagnosis and $41.1 \%$ after diagnosis [11]. The disease stage was also a factor in the patients' susceptibility to using CAM methods. Studies report that CAM use is more common in patients receiving chemotherapy or radiotherapy or combined therapy $[9,15,20]$, in patients with recurrent disease or metastasis [15], and in patients who received their initial diagnosis more than 12 months ago [22]. On the contrary, there are also reports in the medical literature stating that the clinical features of the disease do not affect CAM use [12, 13, 17].

In our study, no statistically significant difference was observed between the Global Health and Functional Area submodules between users and non-users of CAM methods ( $p>0.05)$. When the Symptom submodules' score averages of the users and non-users of CAM methods were compared, nausea and vomiting, dyspnea, and diarrhea were more prominent among CAM users. Patients may be using CAM methods to alleviate these symptoms, or CAM use may in fact lead to the above symptoms.

In studies investigating the association between quality of life and CAM use, the usage rate is found to be higher in patients with low quality of life [16] and in depressed patients [22]. However, there are also studies reporting no significant association between quality of life and CAM use [17]. The quality of life questionnaire (QOL-C30) used in our study has some limitations, namely that it scores the psychosocial status and quality of life in a certain time frame. The physical and emotional problems that the patients were confronted with during the interview, including nausea and vomiting, fatigue and feeling down, the desire to finish the therapy and leave the hospital as soon as possible, or the fact that their relatives 
were accompanying them, all caused difficulties in filling out the questionnaire. On the other hand, low sociocultural levels of the patients may also have had an impact.

\section{Conclusions}

The usage rate and types of CAM vary between patients with breast cancer. The cultural characteristics of the study population, the perception of the health concept, socioeconomic status, and geographic location are among the factors that may cause such variations in the usage rate and types of
CAM methods. In conclusion, there is a need to increase the awareness of health professionals on the use of CAM in the society, on the effects and adverse effects of these methods, and the importance of discussing them with the patients and their families. Evidence-based clinical studies on the efficacy of CAM methods should also be undertaken.

\section{Conflict of Interest}

We do not have any sponsorship or funding arrangements. We do not declare any conflict of interest.

\section{References}

1 Suzuki N: Complementary and alternative medicine: a Japan perspective. Evid Based Complement Alternat Med 2004;1:113-118.

2 http://nccam.nih.gov/ (date 08/02/2008).

- Ernst E: Prevalence of use of complementary / alternative medicine: a systematic review. Bull World Health Organ 2000;78:252-257.

$\checkmark 4$ Tan M, Uzun O, Akcay F: Trends in complementary and alternative medicine in Eastern Turkey. J Altern Complement Med 2004;10:861-865.

$\checkmark 5$ Aslan O, Vural H, Komurcu S, Ozet A: Use of complementary and alternative medicine by cancer patients in Turkey: a survey. J Altern Complement Med 2006;12:355-356.

6 Yildirim Y, Tinar S, Yorgun S, Toz E, Kaya B, Sonmez S, Balsak D: The use of complementary and alternative medicine (CAM) therapies by Turkish women with gynecological cancer. Eur J Gynaecol Oncol 2006;27:81-85.

7 Algier LA, Hanoglu Z, Ozden G, Kara F: The use of complementary and alternative medicine (nonconventional) in cancer patients in Turkey. Eur J Oncol Nurs 2005;9:138-146.

8 Ceylan S, Hamzaoglu O, Komurcu S, Beyhan C, Yalcin A: Survey of the use of complementary and alternative medicine among Turkish cancer patients. Complement Ther in Med 2002;10:94-99.

-9 Tas F, Ustuner Z, Can G, Eralp Y, Camlica H, Basaran M, Karagol H, Sakar B, Disci R, Topuz E: The prevalence and determinants of the use of complementary and alternative medicine in adult Turkish cancer patients. Acta Oncol 2005;44:161-167.

10 Isikhan V, Komurcu S, Ozet A, Arpaci F, Ozturk B, Balbay O, Guner P: The status of alternative treatment in cancer patients in Turkey. Cancer Nurs 2005;28:355-362.
Gozum S, Tezel A, Koc M: Complementary alternative treatments used by patients with cancer in Eastern Turkey. Cancer Nurs 2003;26:230-236.

12 Nagel G, Hoyer H, Katenkamp D: Use of complementary and alternative medicine by patients with breast cancer: observations from a health-care survey. Support Care Cancer 2004;12:789-796.

13 Rakovitch E, Pignol JP, Chartier C, Ezer M, Verma $\mathrm{S}$, Dranitsaris G, Clemons M: Complementary and alternative medicine use is associated with an increased perception of breast cancer risk and death. Breast Cancer Res Treat 2005;90:139-148.

14 Rees RW, Feigel I, Vickers A, Zollman C, McGurk $\mathrm{R}$, Smith C: Prevalence of complementary therapy use by women with breast cancer: a populationbased survey. Eur J Cancer 2000;36:1359-1364.

15 Cui Y, Shu XO, Gao Y, Wen W, Ruan ZX, Jin F, Zheng W: Use of complementary and alternative medicine by Chinese women with breast cancer. Breast Cancer Res Treat 2004;85:263-270.

16 Buettner C, Kroenke CH, Phillips RS, Davis RB, Eisenberg DM, Holmes MD: Correlates of use of different types of complementary and alternative medicine by breast cancer survivors in the nurses' health study. Breast Cancer Res Treat 2006;100: 219-227.

17 Balneaves LG, Kristjanson LJ, Tataryn D: Beyond convention: describing complementary therapy use by women living with breast cancer. Patient Educ Couns 1999;38:143-153.

18 Guzelant A, Goksel T, Ozkok S, Tasbakan S, Aysan T, Bottomley A: The European Organization for Research and Treatment of Cancer QLQ-C30: an examination into the cultural validity and reliability of the Turkish version of the EORTC QLQ-C30. Eur J Cancer Care (Engl) 2004;13:135-144.
9 Eguchi K, Hyodo I, Saeki H: Current status of cancer patients' perception of alternative medicine in Japan: a preliminary cross-sectional survey. Support Care Cancer 2000;8:28-32.

20 Molassiotis A, Scott JA, Kearney N, Pud D, Magri M, Selvekerova S, Bruyns I, Fernadez-Ortega P, Panteli V, Margulies A, Gudmundsdottir G, Milovics L, Ozden G, Platin N, Patiraki E: Complementary and alternative medicine use in breast cancer patients in Europe. Support Care Cancer 2006;14: 260-267.

21 Sibbritt D, Adams J, Easthope G, Young A: Complementary and alternative medicine (CAM) use among elderly Australian women who have cancer. Support Care Cancer 2003;11:548-550.

22 Montazeri A, Sajadian A, Ebrahimi M, Akbari ME: Depression and the use of complementary medicine among breast cancer patients. Support Care Cancer 2005;13:339-342.

23 Gröber U: Antioxidants and other micronutrients in complementary oncology. Breast Care 2009;4: 13-20.

24 Stubert J, Gerber B: Isoflavones-mechanism of action and impact on breast cancer risk. Breast Care 2009;4:22-29.

25 Beuth J: Evidence-based complementary medicine in breast cancer therapy. Breast Care 2009;4:8-12.

26 Ugurluer G, Karahan A, Edirne T, Sahin HA: Ayaktan Kemoterapi Unitesinde Tedavi Alan Hastalarin Tamamlayici ve Alternatif Tip Uygulamalarina Basvurma Sikligi ve Nedenleri. Van Tip Dergisi 2007;14:68-73.

27 Yavuz M, Ilce AO, Kaymakci S, Bildik G, Diramali A: Meme Kanserli Hastalarin Tamamlayici ve Alternatif Tedavi Yontemlerini Kullanma Durumlarinin Incelenmesi. Turkiye Klinikleri 2007;27:680686. 